\title{
Effect of Vagus Nerve Cooling on Hypercapnic and Hypoxic Ventilatory Responses in Anesthetizes Dogs
}

\author{
Yuzo Sagara, Kaoru Koike, Takamasa Ohnuki, * Sumio \\ NitTa* and Tasuku Nakada
}

Department of Surgery, the Research Institute for Tuberculosis and Cancer, Tohoku University, Sendai 980 and *Tokyo Women's Medical College, Tokyo 162

\begin{abstract}
Sagara, Y., Kolke, K., Ohnuki, T., Nitta, S. and Nakada, T. Effect of Vagus Nerve Cooling on Hypercapnic and Hypoxic Ventilatory Responses in Anesthetized Dogs. Tohoku J. Exp. Med., 1988, 156, Suppl., 83-91 — We studied ventilatory responses under hypercapnic and hypoxic conditions in 18 lightly anesthetized dogs, using a vagus nerve cooling technique. One side of the cervical vagosympathetic trunks of dogs were previously severed, and a copper cooling probe was attached to the other side. When the cervical nerve was cooled below $7^{\circ} \mathrm{C}$, Hering-Breuer inflation reflex ceased. We found that when the vagus nerve was not cooled or cooled up to $7^{\circ} \mathrm{C}$, the respiratory frequency increased significantly in relation to hypereapnic gas inhalation. However, the increment of respiratory frequency was reduced by bilateral cervical vagotomy. On the other hand, the respiratory frequency in response to hypoxia increased significantly, even when bilateral vagotomy was done. The increment of the tidal volume in response to hypercapnic gas inhalation was reduced by the Hering-Breuer inflation reflex. We found that the effect of the vagus nerve on respiratory regulation was different between hypercapnic and hypoxic gas inhalation.-Hering-Brever inflation reflex; vagus nerve cooling; hypercapnia; hypoxia
\end{abstract}

The fact that bilateral cervical vagotomy causes slow, deep breathing is well known. It has been thought that the pulmonary stretch receptor stimulated by lung inflation sends impulses to the central respiratory center, mediated by the vagus nerve. So the Hering-Breuer inflation reflex has been thought to influence respiratory frequency and tidal volume. Phillipson et al. (1973) utilized a vagal cooling technique in dogs and found that reduction of the increment of the respiratory frequency response to hypercapnia was related to the cessation of the Hering-Breuer inflation reflex. They concluded that the increase in respiratory frequency during hypercapnia was due to the irritant receptor. However, Russell et al. (1984) concluded that respiratory frequency with hypercapnic gas inhalation increased due to stimuli from the $\mathrm{C}$-fiber receptor, because, they found utilizing the anodal block technique in rabbits, that the increment of the respiratory frequency was reduced by blockade of the $\mathrm{C}$-fiber. It has not been clarified 
how the Hering-Breuer inflation reflex and other vagally mediated stimuli affect the hypoxic respiratory response.

The purpose of this study is to elucidate how the Hering-Breuer inflation reflex and other vagally mediated stimuli affect hypercapnic and hypoxic respiratory responses. The Hering-Breuer inflation reflex is mediated by large myelinated fiber (Widdicombe 1981), so this reflex is blocked at a slightly higher temperature than other vagally mediated afferent drives. We used a cooling technique for differential vagal block in lightly anesthetized dogs. Our investigation showed that vagally mediated stimuli affect the respiratory center in different ways in response to hypercapnia and hypoxia.

\section{Materials and Methods}

\section{Surgical preparation}

We anesthetized 18 dogs $(8-15 \mathrm{~kg})$ with intramuscular ketamin hydrochloride $(15 \mathrm{mg} /$ $\mathrm{kg}$; Sankyo, Tokyo) and intravenous sodium pentobarbital (25 mg/kg; Tokyo Kasei, Tokyo), inserted an endotracheal tube, and mainteined anesthesia by continuous intravenous infusion of chloralose $(20 \mathrm{mg} / \mathrm{kg} / \mathrm{hr}$; Wakou Junyaku, Osaka) and urethane (200 $\mathrm{mg} / \mathrm{kg} / \mathrm{hr}$; Tokyo Kasei). A vertical incision was made on the right side of the cervix and Swan-Ganz catheter (Edwards, Sant Ana, CA, VSA) was inserted into the pulmonary artery through the right jugular vein for maintenance of anesthesia. The right cervical vagosympathetic trunk was cut at the level of the 4 th cervical vertebra. We inserted a catheter into the abdominal aorta through the right fermoral artery to measure the systemic blood pressure. We made a vertical incision on the left side of the cervix and dissected the left cervical vagosympathetic trunk for about $5 \mathrm{~cm}$ long at about $8 \mathrm{~cm}$ peripheral to the distal vagal ganglion.

\section{Vagus nerve cooling}

A $10 \mathrm{~mm}$ copper cube with a $5 \mathrm{~mm}$ groove in width running down the center of the surface was attached to the nerve, as a cooling probe. This cube was covered with silicon except the surface groove where the nerve was attached. The cube was perfused with water having a temperature of $37^{\circ} \mathrm{C}$ in the control experiment and with water a temperature of $7^{\circ} \mathrm{C}$ in the vagus nerve cooling experiment. A pump (MPS-15-2, Senko Medical Industry, Tokyo) with a heat exchanger was employed for this perfusion. We continuously measured the temperature within the circuit by means of a digital thermistor (673, Sibata, Taiwan).

\section{Experimental protocol}

To determine the effects of vagus nerve cooling on ventilatory responses under hypercapnic and hypoxic conditions, we divided the animals into two groups; hypercapnic ( $n=$ 9 ) and hypoxic $(n=9)$ groups. We allowed the animals to breath spontaneously for at least $2 \mathrm{hr}$ after surgery and then started the experiments.

In the control experiment of the hypercapnic group, the left vagosympathetic trunk in the groove of the nerve cooler was perfused with $37^{\circ} \mathrm{C}$ water. Then we clamped the endotracheal tube and inflated the lungs by the rapid injection of about $400 \mathrm{ml}$ air into the tube untill the airway pressure rose to $20-30 \mathrm{mmHg}$. Animals exhibiting apnea for $30 \mathrm{sec}$ were determined as having the inflation reflex. Then, clamping the endotracheal tube was released. The animals were left in room air for $10 \mathrm{~min}$ to ensure stable breathing, and then all variables were measured. The animals were the subjected to hypercapnic test, rebreathing $7 \% \mathrm{CO}_{2}+20 \% \mathrm{O}_{2}$ in $\mathrm{N}_{2}$ for $5 \mathrm{~min}$, and all variables were measured. In the vagus nerve cooling experiment, we perfused the nerve cooling probe with water at $37^{\circ} \mathrm{C}$. We inflated 
the lung as described above and found that the inflation reflex had ceased. The animals were placed in room air and all variables were measured. Then the animals subjected to hypercapnic test and all variables were again measured. The animals were then again placed in room air, and we reconfirmed that the inflation reflex had ceased by the same method as used at the beginning of this period. In the vagotomy experiment, we measure all variables under room air and hypercapnic trials after severing the left cervical vagosympathetic trunk. These experiments were conducted by using the same animals.

In the hypoxic group, we confirmed the presence of the inflation reflex at the beginning of the control experiments. In the control, vagus nerve cooling and vagotomy experiments, we measured all variables by the same protocol as employed in the experiments with the hypercapnic groups. We used $5 \% \mathrm{CO}_{2}+20 \% \mathrm{O}_{2}$ in $\mathrm{N}_{2}$ and $5 \% \mathrm{CO}_{2}+10 \% \mathrm{O}_{2}$ in $\mathrm{N}_{2}$ gas instead of room air and $7 \% \mathrm{CO}_{2}+20 \% \mathrm{O}_{2}$ in $\mathrm{N}_{2}$ gas.

\section{Measurement}

We measured the airway pressure with a calibrated gauge (P50, Gould Statham, Hato Rey, Puerto Rico) passing through a catheter that was placed in the endotracheal tube. We continuously measured the respiratory frequency $(f)$, the tidal volume $\left(V_{T}\right)$ and the expired minute ventilaion $\left(\dot{\mathrm{V}}_{\mathrm{E}}\right)$ by pneumotachogragh (47303A, Hurett-Pakkard, Waltham, MA, USA). We collected heparinized arterial blood samples at the end of each test period to measure the blood gases and $\mathrm{pH}$ by blood gas analyzer (ABL2, Radiometer, Copenhagen, Denmark). We measured the fractions of $\mathrm{O}_{2}$ and $\mathrm{CO}_{2}$ in inhalation gas by the Scholander method.

\section{Data analysis}

We averaged the ventilatory responses for $30 \mathrm{sec}$ at the end of 5-min gas inhalation. This value was assumed to indicate the response to this gas inhalation. We caliculated the ratio of increase of respiratory frequency, tidal volume and expired minute ventilation per unit change in $\mathrm{PaCO}_{2}$ and $\mathrm{SaO}_{2}\left(\Delta \mathrm{f} / \mathrm{f}_{0} / \Delta \mathrm{PaCO}_{2}, \Delta \mathrm{V}_{\mathrm{T}} / \mathrm{V}_{\mathrm{TO}} / \Delta \mathrm{PaCO}_{2}, \Delta \dot{\mathrm{V}}_{\mathrm{E}} / \dot{\mathrm{V}}_{\mathrm{E} 0} / \Delta \mathrm{PaCO}_{2}\right.$, $\left.\Delta \mathrm{f} / \mathrm{f}_{0} / \Delta \mathrm{SaO}_{2}, \Delta \mathrm{V}_{\mathrm{T}} / \mathrm{V}_{\mathrm{TO}} / \Delta \mathrm{SaO}_{2}, \Delta \dot{\mathrm{V}}_{\mathrm{E}} / \dot{\mathrm{V}}_{\mathrm{EO}} / \Delta \mathrm{SaO}_{2}\right)$ as indicator of responsiveness for hypercapnic and hypoxic gas inhalation, where $\Delta \mathrm{f}, \Delta \mathrm{V}_{\mathrm{T}}$ and $\Delta \dot{\mathrm{V}}_{\mathrm{E}}$ are the increments of respiratory frequency, tidal volume and expired minute ventilation due to the hypercapnic and hypoxic gas inhalation; $f_{0}, V_{T 0}$ and $\dot{V}_{E_{0}}$ are the respiratory frequency, tidal volume and expired minute ventilation before the hypercapnic and hypoxic gas inhalation respectively; $\triangle \mathrm{PaCO}_{2}$ is the increment of $\mathrm{PaCO}_{2}$ caused by hypercapnic gas inhalation, and $\triangle \mathrm{SaO}_{2}$ is the decrement of $\mathrm{SaO}_{2}$ due to hypoxic gas inhalation.

Statistical analysis was done by Student's $t$-test for paired variables, and $p<0.05$ was considered to be significant.

\section{Results}

During the experiments, the ciliary reflex of the animals existed. We confirmed that the apnea time due to the Hering-Breuer inflation reflex continued more than $30 \mathrm{sec}$ in the control group, and that the Hering-Breuer inflation reflex ceased due to vagus nerve cooling as shown in Fig. 1.

\section{Hypercapnic response}

The composition of gas used for the hypercapnic experiments were $7 \% \mathrm{CO}_{2}$ and $21 \% \mathrm{O}_{2}$ in $\mathrm{N}_{2}$. The summarized data of the ventilatory responses and arterial blood gases are shown in Table 1. Vagus nerve cooling and vagotomy did not affect the respiratory frequencies under normocapnic conditions. In the 

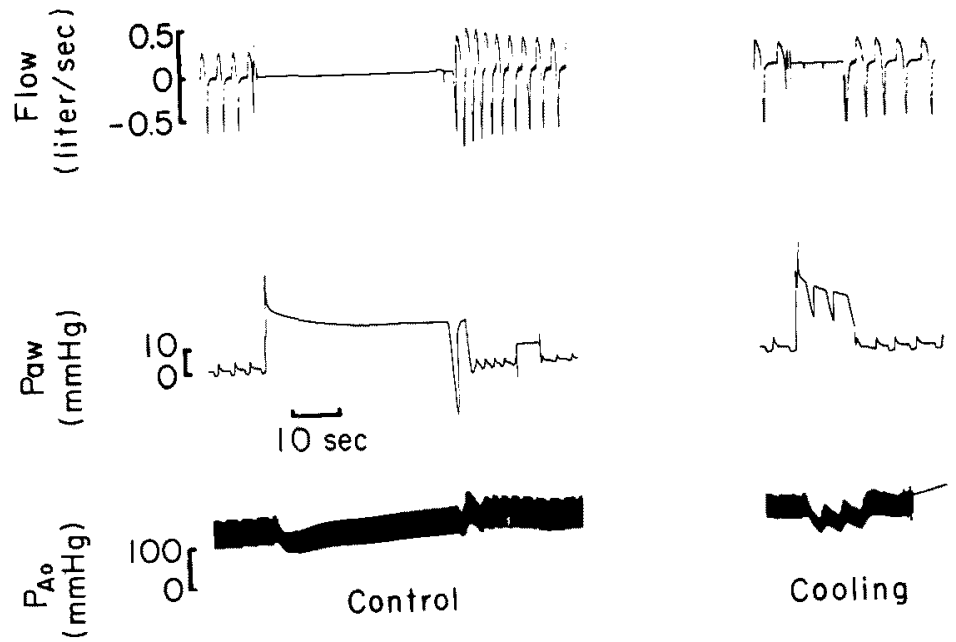

Fig. 1. Apnea time due to the Hering-Breuer inflation reflex continued more than $30 \mathrm{sec}$ in the control group, and the Hering-Breuer inflation reflex ceased due to vagal nerve cooling.

hypercapnic experiments, vagus nerve cooling did not affect the respiratory frequency, but vagotomy caused respiratory frequency to decrease in 8 of 9 dogs. Comparing vagus nerve cooling and vagotomy, respiratory frequency was significantly less in vagotomy. The ratio of increment of respiratory frequency per unit $\mathrm{PaCO}_{2}$ change was significantly less in vagotomy compared to the control and vagus nerve cooling groups. Vagus nerve cooling and vagotomy caused tidal volume to increase significantly under both normo- and hypercapnic conditions.

TABLE 1. Vantilatory responses in control, vagal nerve cooling and

\begin{tabular}{lcccc}
\multicolumn{1}{c}{ Condition } & $n$ & $\begin{array}{c}\mathrm{f} \\
(\text { breath } / \mathrm{min})\end{array}$ & $\begin{array}{c}\mathrm{V}_{\mathrm{T}} \\
(\mathrm{ml})\end{array}$ & $\begin{array}{c}\dot{\mathrm{V}}_{\mathrm{E}} \\
\text { (liter } / \mathrm{min})\end{array}$ \\
\hline Room air & 9 & & & \\
$\quad$ Control & & $14.4 \pm 3.6$ & $279 \pm 67$ & $4.1 \pm 1.6$ \\
$\quad$ Vagal nerve cooling & & $14.4 \pm 4.9$ & $361 \pm 126^{*}$ & $5.1 \pm 2.5^{*}$ \\
$\quad$ Vagotomy & & $14.3 \pm 4.7$ & $346 \pm 125^{*}$ & $4.7 \pm 1.8$ \\
$7 \% \mathrm{CO}_{2}$ & 9 & & & \\
Control & & $22.7 \pm 5.2$ & $503 \pm 191$ & $11.8 \pm 6.4$ \\
Vagal nerve cooling & & $23.7 \pm 7.1$ & $742 \pm 247^{*}$ & $18.1 \pm 9.4^{*}$ \\
Vagotomy & & $17.9 \pm 5.0 \dagger$ & $850 \pm 390^{*}$ & $15.7 \pm 10.0^{*}$ \\
\hline
\end{tabular}

Results are given as mean \pm S.D.

${ }^{*} p<0.05$ against corresponding control values (paired $t$-test).

$\dagger p<0.05$ against corresponding values during vagus nerve cooling (paired $t$-test).

$n$, numbers of dogs; $f$, respiratory frequency; $\mathrm{V}_{\mathrm{T}}$, tidal volume; $\dot{\mathrm{V}}_{\mathrm{E}}$, expired $\mathrm{PaCO}_{2} \Delta \mathrm{V}_{\mathrm{T}} / \mathrm{V}_{\mathrm{ro}} / \Delta \mathrm{PaCO}_{2}$, ratio of increment of tidal volume per unit $\mathrm{PaCO}_{2}$; 
Under hypoxic conditions, vagus nerve cooling and vagotomy caused the ratio of increment of tidal volume per unit $\mathrm{PaCO}_{2}$ change to increase. Under normocapnic conditions, vagus nerve cooling caused expired minute ventilation to increase, but vagotomy did not. Under hypercapnic conditions, both vagus nerve cooling and vagotomy caused expired minute ventilation to increase. There was no difference in the ratio of increment of expired minute ventilation per unit $\mathrm{PaCO}_{2}$ among the three conditions. There was no difference in $\mathrm{PaCO}_{2}$ among the three conditions in hypercapnic gas inhalation experiments.

\section{Hypoxic response}

The composition of gas used for the normoxic experiments were $20 \% \mathrm{O}_{2}$ and $5 \% \mathrm{CO}_{2}$ in $\mathrm{N}_{2}$, and for hypoxic experiments were $10 \% \mathrm{O}_{2}$ and $5 \% \mathrm{CO}_{2}$ in $\mathrm{N}_{2}$. The summarized data of ventilatory response and arterial blood gases are shown in Table 2. Vagus nerve cooling and vagotomy did not affect the respiratory frequency under normo- and hypoxic conditions. But the respiratory frequency was significantly less in vagotomy compared to the vagus nerve cooling under nomoxic conditions. Vagus nerve cooling and vagotomy did not affect the ratio of increment in respiratory frequency per unit $\mathrm{SaO}_{2}$ depression. Vagus nerve cooling and vagotomy caused expired minute ventilation to increase significantly under normo- and hypoxic conditions and did not affect the ratio of increment in expired minute ventilation per unit $\mathrm{SaO}_{2}$. There was no difference in $\mathrm{PaCO}_{2}$ among the three conditions in normo- and hypoxic gas inhalation experiments.

\section{DisCUSSION}

Our results show that the cervical vagosympathetic trunks regulate respira-

vagotomy groups to normo-and hypercapnic gas inhalation in anesthetized dogs

\begin{tabular}{|c|c|c|c|c|}
\hline $\begin{array}{c}\Delta \mathrm{f} / \mathrm{f}_{\mathrm{o}} / \Delta \mathrm{PaCO}_{2} \\
\text { (ratio/torr) }\end{array}$ & $\underset{\text { (ratio/torr) }}{\Delta \mathrm{V}_{\mathrm{r}} / \mathrm{V}_{\text {ro }} / \Delta \mathrm{PaCO}_{2}}$ & $\begin{array}{c}\Delta \dot{\mathrm{V}}_{\mathrm{E}} / \dot{\mathrm{V}}_{\mathrm{EO}} / \Delta \mathrm{PaCO}_{2} \\
\text { (ratio/torr) }\end{array}$ & $\underset{\text { (torr) }}{\mathrm{PaCO}_{2}}$ & $\begin{array}{l}\mathrm{PaO}_{2} \\
\text { (torr) }\end{array}$ \\
\hline & & & $41 \pm 5$ & $92 \pm 10$ \\
\hline & & & $39 \pm 4$ & $95 \pm 11$ \\
\hline & & & $39 \pm 5$ & $95 \pm 11$ \\
\hline $0.04 \pm 0.01$ & $0.05 \pm 0.02$ & $0.12 \pm 0.05$ & $56 \pm 4$ & $118 \pm 11$ \\
\hline $0.05 \pm 0.03$ & $0.08 \pm 0.02^{*}$ & $0.18 \pm 0.07$ & $54 \pm 6$ & $123 \pm 12$ \\
\hline $0.02 \pm 0.01^{*}, \dagger$ & $0.09 \pm 0.04^{*}$ & $0.14 \pm 0.05$ & $55 \pm 4$ & $124 \pm 13$ \\
\hline
\end{tabular}

minute ventilation; $\Delta \mathrm{f} / \mathrm{f}_{\mathrm{o}} / \Delta \mathrm{PaCO}_{2}$, ratio of increment of respiratory frequency per unit $\Delta \dot{\mathrm{V}}_{\mathrm{E}} / \dot{\mathrm{V}}_{\mathrm{E} O} / \Delta \mathrm{PaCO}_{2}$, ratio of increment of expired minute ventilation per unit $\mathrm{PaCO}_{2}$. 
TABLE 2. Ventilatory responses in control, vagal nerve cooling and

\begin{tabular}{lcccc}
\multicolumn{1}{c}{ Condition } & $n$ & $\begin{array}{c}\mathrm{f} \\
\text { (breath/min) }\end{array}$ & $\begin{array}{c}\mathrm{V}_{\mathrm{T}} \\
(\mathrm{ml})\end{array}$ & $\begin{array}{c}\dot{\mathrm{V}}_{\mathrm{E}} \\
\text { (liter/min) }\end{array}$ \\
\hline $5 \% \mathrm{CO}_{2}+20 \% \mathrm{O}_{2}$ in $\mathrm{N}_{2}$ & 9 & & & \\
$\quad$ Control & & $18.2 \pm 7.0$ & $404 \pm 129$ & $6.7 \pm 1.3$ \\
$\quad$ Vagal nerve cooling & & $18.3 \pm 10.9$ & $578 \pm 232^{*}$ & $8.8 \pm 2.1^{*}$ \\
$\quad$ Vagotomy & & $15.2 \pm 10.8 \dagger$ & $704 \pm 273 \dagger$ & $8.7 \pm 2.6^{*}$ \\
$5 \% \mathrm{CO}_{2}+10 \% \mathrm{O}_{2}$ in $\mathrm{N}_{2}$ & 9 & & & \\
$\quad$ Control & & $25.6 \pm 9.7$ & $452 \pm 127$ & $10.9 \pm 4.0$ \\
$\quad$ Vagal nerve cooling & & $25.7 \pm 12.6$ & $702 \pm 254^{*}$ & $15.8 \pm 5.0^{*}$ \\
$\quad$ Vagotomy & & $23.2 \pm 12.3$ & $818 \pm 314 \dagger$ & $16.4 \pm 4.5^{*}$ \\
\hline
\end{tabular}

Results are given as mean \pm s.D.

${ }^{*} p<0.05$ against corresponding control values (paired $t$-test).

$\dagger p<0.05$ against corresponding values during vagus nerve cooling (paired $t$-test).

$n$, numbers of dogs; $f$, respiratory frequency; $\mathrm{V}_{\mathrm{T}}$, tidal volume; $\dot{\mathrm{V}}_{\mathrm{E}}$, expired $\mathrm{SaO}_{2} ; \Delta \mathrm{V}_{\mathrm{T}} / \mathrm{V}_{\mathrm{TO}} / \Delta \mathrm{SaO}_{2}$, ratio of increment of tidal volume per unit $\mathrm{SaO}_{2}$;

tory frequency under hypercapnic conditions, and do not contribute to the control of respiration under hypoxic conditions. In hypercapnic gas inhalation experiments, vagus nerve cooling did not influence respiratory frequency, but vagotomy caused frequency to decrease. The ratio of increment in respiratory frequency per unit $\mathrm{PaCO}_{2}$ was also significantly smaller under vagotomized conditions than under control and vagus nerve cooling conditions. These results suggest that the cervical vagosympathetic trunks regulate the increment of the respiratory frequency due to hypercapnic conditions. It has been known that there are three peripheral receptors in lungs : the pulmonay stretch receptors, irritant receptors and J-receptors (Sant' Ambrogio 1982). In the cervical vagosympathetic trunks, there are two kinds of fiber; myelinated and non-myelinated fibers. The myelinated fibers, in which conduction is blocked by temperatures of $7-19^{\circ} \mathrm{C}$, are the fibers from the pulmonary stretch receptors and the irritant receptors (Widdicombe 1964). We decided on a cooling temperature of $7^{\circ} \mathrm{C}$, as it was the highest temperature at which the Hering-Breuer inflation reflex was assumed to be ceased in all dogs in our experiments. The non-myelinated fibers, which is not blocked by a temperature of $7^{\circ} \mathrm{C}$, conduct the stimuli from J-receptors (Coleridge and Coleridge 1984). Phillipson et al. (1973) reported that irritant receptors were responsible for the increment of the respiratory frequency due to hypercapnic conditions. However, Russell et al. (1984) showed that the non-myelinated fibers, which conduct the stimuli from the $J$-receptors, were responsible for the increment of frequency under hypercapnic conditions by using the anodal block technique. We found that vagus nerve cooling did not affect respiratory frequency and that vagotomy caused a reduction in the increment of the respiratory frequency under hypercapnic conditions; this suggests that non-myelinated 
vagotomy groups to normo- and hypoxic gas inhalation in anesthetized dogs

\begin{tabular}{ccccc}
\hline $\begin{array}{c}\Delta \mathrm{f}_{\text {(ratio/torr) }} / \Delta \mathrm{SaO}_{2} \\
\end{array}$ & $\begin{array}{c}\Delta \mathrm{V}_{\mathrm{T}} / \mathrm{V}_{\mathrm{ro} /} / \mathrm{SaO}_{2} \\
\text { (ratio/torr) }\end{array}$ & $\begin{array}{c}\mathrm{SaO}_{2} \\
(\%)\end{array}$ & $\begin{array}{c}\mathrm{PaCO}_{2} \\
\text { (torr) }\end{array}$ & \\
\hline & & & $97 \pm 1$ & $43 \pm 4$ \\
& & & $97 \pm 1$ & $42 \pm 3$ \\
& & & $97 \pm 1$ & $42 \pm 3$ \\
$0.04 \pm 0.03$ & $0.01 \pm 0.01$ & & & \\
$0.07 \pm 0.05$ & $0.03 \pm 0.02$ & $0.07 \pm 0.05$ & $87 \pm 3$ & $40 \pm 2$ \\
$0.09 \pm 0.07$ & $0.02 \pm 0.02$ & $0.11 \pm 0.07$ & $89 \pm 2 \dagger$ & $39 \pm 2$ \\
\hline
\end{tabular}

minute ventilation; $\Delta \mathrm{f} / \mathrm{f}_{\mathrm{o}} / \Delta \mathrm{SaO}_{2}$, ratio of increment of respiratory frequency per unit $\Delta \dot{\mathrm{V}}_{\mathrm{E}} / \dot{\mathrm{V}}_{\mathrm{ET}} / \Delta \mathrm{SaO}_{2}$, ratio of increment of expired minute ventilation per unit $\mathrm{SaO}_{2}$.

fibers, which conduct the stimuli from the J-receptors, increase respiratory frequency under conditions of hypercapnic gas inhalation. Pulmonary stretch receptors, irritant receptors and $J$-receptors respond to lung inflation. It is known that hypercapnia by itself is not sufficient to cause responses of irritant receptors and J-receptors (Sant' Ambrogio 1982). So we concluded that the vagosympathetic trunk which was blocked at a temperature lower than $7^{\circ} \mathrm{C}$ was stimulated by lung inflation and that the increase in respiratory frequency under hypercapnia was influenced mainly by the stimulus of this inflation. Vagus nerve cooling and vagotomy caused tidal volume to increase with room air breathing and hypercapnic gas inhalation. The ratio of increment in tidal volume per unit $\mathrm{PaCO}_{2}$ rise was higher during vagus nerve cooling and vagotomy conditions than under control condition. These results suggest that the increment of the tidal volume caused by hypercapnic gas inhalation is restricted by the Hering-Breuer inflation reflex which is blocked by vagal nerve cooling. Vagus nerve cooling caused the expired minute ventilation to increase under conditions of room air breathing and hypercapnic gas inhalation. Vagotomy increased expired minute ventilation under hypercapnic conditions. But there was no difference in the ratio of increment in expired minute ventilation per unit $\mathrm{PaCO}_{2}$ among these three conditions. Lim et al. (1958) reported that the respiratory center of a vagotomized dog increased its sensitibity to $\mathrm{PaCO}_{2}$ and that the expired minute ventilation became greater. Our results suggest that vagotomy causes an increase in expired minute ventilation with hypercapnic gas inhalation.

In hypoxic experiments, dogs were inhalated with $5 \% \mathrm{CO}_{2}$ before and during hypoxic loading to maintain the stability of the $\mathrm{PaCO}_{2}$ level despite hyperventilation induced hypoxia. Respiratory frequency was significantly less under 
vagotomized conditions than under vagus nerve cooling conditions before hypoxic gas inhalation. We concluded that this was due to the effect of $5 \% \mathrm{CO}_{2}$. The respiratory frequency and the ratio of increment in respiratory frequency per unit $\mathrm{SaO}_{2}$ were not significantly different among control, vagus nerve cooling and vagotomy conditions under hypoxic gas inhalation. So we concluded that the vagus nerve did not increase respiratory frequency during hypoxic loading. The tidal volume was greater under conditions of vagus nerve cooling and vagotomy than under control conditions before and during hypoxic gas inhalation. However, there was no difference in the ratio of increment in tidal volume per unit $\mathrm{SaO}_{2}$ among the three conditions. We concluded that the tidal volume during hypoxic loading was reflected by the effects of the $5 \% \mathrm{CO}_{2}$ gas mixture. The effect of the vagus nerve seemed to be less under hypoxic conditions than under hypercapnic conditions. The expired minute ventilation was greater under conditions of vagus nerve cooling and vagotomy than under control conditions before and during hypoxic gas inhalation. But there was no difference in the expired minute ventilation among the three conditions. We concluded that the expired minute ventilation during hypoxic gas inhalation was also reflected by the effects of $5 \% \mathrm{CO}_{2}$ gas mixture and that strength of the output from the respiratory centers overcame the input from the vagus nerve during hypoxic gas inhalation.

In our experiments, one side of the cervical vagosympathetic trunks was previously severed due to technical problems. Phillipson et al. (1971) showed that blockade of one side of cervical vagosympathetic trunks abolished the Hering-Breuer inflation reflex in a conscious dog. However, it has been reported that, in an anesthetized dog, the Hering-Breuer inflation reflex was reduced but continue to exsist when one side of the vagosympathetic trunks was severed (Lim et al. 1958). We did not use dogs whose apnea time did not continue for more than $30 \mathrm{sec}$ when their endotracheal pressure rose to $20-30 \mathrm{mmHg}$ after severance of one side of the vagosympathetic trunks. Thus we concluded that the HeringBreuer inflation reflex was strong enough to inhibit inspiratory drive from the respiratory center.

In our experiments, the data regarding blood gases under conditions of room air breathing were within normal values for unanesthetized dogs (Feigl and Dalecy 1972). Also, the experiments were done under conditions in which the ciliary reflex continued to exist, so it seemed that the depth of anesthesia was considered to be maintained to a moderate degree (Chonan et al. 1984).

\section{References}

1) Chonan, T., Kikuchi, Y., Hida, W., Shindoh, C., Inoue, H., Sasaki, H. \& Takishima, T. (1984) Response to hypercapnia and exercise hyperpnea in graded anesthesia. J. Appl. Physiol., 57, 1796-1802.

2) Coleridge, J.C.G. \& Coleridge, H.M. (1984) Afferent vagal C fiber innervation of the lungs and airways and its functional significance. Rev. Physiol. Biochem. Pharmacol., 99, 1-100. 
3) Feigl, E.O. \& D'alecy, L.G. (1972) Normal arterial blood pH, oxygen and carbon dioxide tension in unanesthetized dogs. J. Appl. Physiol., 32, 152-153.

4) Lim, T.P.K., Luft, U.C. \& Grodins, F.S. (1958) Effect of cervical vagotomy on pulmonary ventilaton and mechanics. J. Appl. Physiol., 13, 317-324.

5) Phillipson, E.A., Hickey, R.F., Graf, P.D. \& Nadal, J.A. (1971) Hering-Breuer inflation reflex and regulation of breathing in conscious dogs. J.Appl. Physiol., 31, 746-750.

6) Phillipson, E.A., Fishman, N.H., Hickey, R.F. \& Nadal, J.A. (1973) Effect of differential vagal blockade on ventilation responses to $\mathrm{CO}_{2}$ in awake dogs. J.Appl. Physiol., 34, 759-763.

7) Russell, N.J.W., Raybould, H.E. \& Trenchard, D. (1984) Role of vagal C-fiber afferents in respiratory response to hypercapnia. J. Appl. Physiol., 56, 1550-1558.

8) Sant' Ambrogio, G. (1982) Information arising from the tracheobronchial tree of mammals. Physiol. Rev., 62, 531-569.

9) Widdicombe, J.G. (1964) Respiratory reflexes. In: Handbook of Physiology, Section 3, Respiration, Vol. 1, edited by W.O. Fenn \& H. Rahn, Amer. Physiol. Soc., Wash. D.C., pp. 585-630.

10) Widdicombe, J.G. (1981) Nervous receptors in the respiratory tract and lungs. In: Regulation of Breathing, Part 1, edited by T.F. Horbein, Dekker, New York, pp. 429472 . 